\title{
Pathology of coronary arteries, myocardium, and . great arteries in supravalvular aortic stenosis
}

\author{
Report of five cases with implications for surgical treatment
}

Among five patients with supravalvular aortic stenosis in whom autopsy tissues were available, all were male, 11/2 to 39 years old (mean 10 years, median 3 years), and the four children had Williams-Beuren syndrome (two familial, two sporadic). Medial thickening and dysplasia (disorganization) characterized the aortic sinotubular junction of three patients with discrete disease and the entire ascending aorta and arch branches of the two with diffuse disease. Medial dysplasia also involved the pulmonary arteries in each case, but less severely than the aorta. Dysplasia of coronary arteries was observed in all five hearts and was more obstructive proximally than distally, in cases with diffuse than discrete aortic disease, and in the adult than in the two children with discrete supravalvular aortic stenosis. All major epicardial arteries were involved, without predilection for any particular vessel. In contrast to the great arteries, coronary artery dysplasia involved all three layers, not just the media. To varying degrees, vessels showed intimal hyperplasia, fibrosis, and disorganization (dysplasia); disruption and loss of the internal elastic membrane, with indistinct intimal-medial junctions; medial hypertrophy and dysplasia; and adventitial fibroelastosis. In severe cases, the microscopic structure resembled that of the ductus arteriosus. Acute intramedial dissections were observed in the ascending aorta and distal right coronary artery in one patient each. Chronic microfocal ischemic fibrosis was identified in the subendocardium and papillary muscles of the left ventricle in four patients, and the adult patient also had an acute myocardial infarction. In summary, these findings emphasize the extraaortic extent of supravalvular aortic stenosis and the development of ischemic heart disease even in childhood. The presence of severe coronary obstruction in the adult with discrete aortic disease suggests that chronic high pulsatile coronary blood pressure may favor the proliferation of dysplastic tissue. Early surgical intervention may minimize the degree of proliferation, as well as allow regression of left ventricular hypertrophy, thereby lessening the risk of myocardial ischemia and aortic dissection. ( $J$ THORAC CARDIOvasC SURG 1994;108:21-8)

Jacques A. M. van Son, MD, PhD, William D. Edwards, MD, and Gordon K. Danielson, MD, Rochester, Minn.

C ongenital supravalvular aortic stenosis represents a developmental complex that is characterized by localized or diffuse narrowing of the ascending aortic lumen com-

From the Division of Thoracic and Cardiovascular Surgery and the Division of Anatomic Pathology, Mayo Clinic, Rochester, Minn.

Received for publication Oct. 1, 1993.

Accepted for publication Dec. 8, 1993.

Address for reprints: William D. Edwards, MD, Hilton (11) Pathology, Mayo Clinic, Rochester, MN 55905.

Copyright $\odot 1994$ by Mosby-Year Book, Inc.

$0022-5223 / 94 \$ 3.00+0 \quad 12 / 1 / 54002$ mencing at the sinotubular junction (Fig. 1). Additional manifestations of the complex include stenoses in the pulmonary arteries and proximal aortic arch vessels, aortic valve dysplasia, and coronary ostial stenoses. ${ }^{1-5}$ In a recent review of the Mayo Clinic experience with the surgical treatment for supravalvular aortic stenosis, ostial and distal coronary arterial lesions and myocardial scarring were described from the autopsy reports from patients who died. ${ }^{6}$ These findings prompted us to perform a detailed histologic investigation of the coronary arteries, myocardium, and great arteries in supravalvular aortic stenosis. 

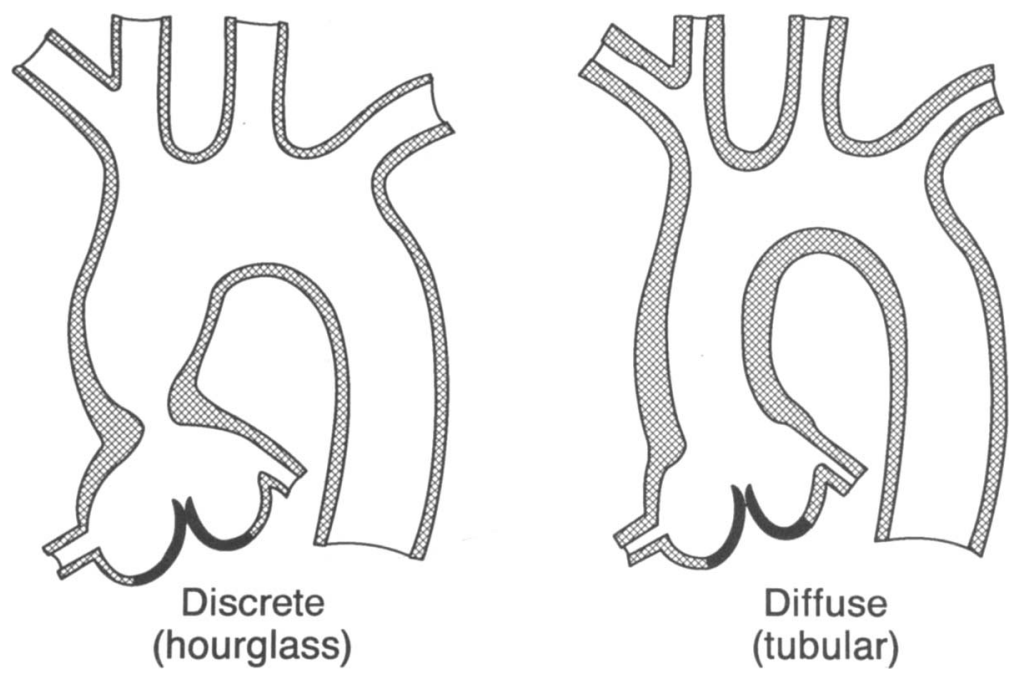

Fig. 1. Schematic diagram of discrete and diffuse forms of supravalvular aortic stenosis.

Table I. Pathologic features of five patients with supravalvular aortic stenosis

\begin{tabular}{|c|c|c|c|c|c|c|c|c|}
\hline \multirow[b]{2}{*}{$\begin{array}{l}\text { Case } \\
\text { No. }\end{array}$} & \multirow[b]{2}{*}{$\begin{array}{l}\text { Age } \\
(y r)\end{array}$} & \multirow[b]{2}{*}{$\begin{array}{l}\text { Year of } \\
\text { autopsy }\end{array}$} & \multirow{2}{*}{$\begin{array}{c}\text { Williams- } \\
\text { Beuren } \\
\text { syndrome }\end{array}$} & \multirow[b]{2}{*}{$\begin{array}{c}S V A S \\
\text { type }\end{array}$} & \multicolumn{3}{|c|}{ Grade of dysplasia } & \multirow[b]{2}{*}{ Other cardiac lesions } \\
\hline & & & & & $\begin{array}{l}\text { Asc } \\
\text { Ao }\end{array}$ & $\begin{array}{c}\text { Arch } \\
\text { branch }\end{array}$ & $P A$ & \\
\hline 1 & 2 & 1978 & Familial & Diffuse & 3 & 3 & 2 & Dissection (Asc Ao) \\
\hline 2 & 3 & 1959 & Sporadic & Diffuse & 2 & 2 & 2 & Dysplastic MV \\
\hline 3 & $11 / 2$ & 1983 & Familial & Discrete & 2 & 0 & 1 & $\begin{array}{l}\text { Left coronary ostial stenosis, } \\
\text { dysplastic MV, PDA }\end{array}$ \\
\hline 4 & 5 & 1980 & Sporadic & Discrete & 1 & 0 & 1 & $\begin{array}{l}\text { Dysplastic AV, left } \\
\text { SVC, others* }\end{array}$ \\
\hline 5 & 39 & 1985 & No & Discrete & 3 & 0 & 2 & Bicuspid AV \\
\hline
\end{tabular}

$A s c A o$, Ascending aorta; $A r c h$ branch, aortic arch branches; $A V$, aortic valve; $M V$, mitral valve; $P D A$, patent ductus arteriosus; $P A$, pulmonary arteries; $S V A S$. supravalvular aortic stenosis; $S V C$, superior vena cava.

*Aplastic left parathyroids and left lobe of thymus, horseshoe kidney, and hypospadia.

\section{Patients and methods}

From the tissue registry of the Mayo Clinic, five hearts with supravalvular aortic stenosis were identified and reviewed by a cardiac pathologist (W.D.E.). The histologic findings in one heart (Table I, case 2) have been reported previously. ${ }^{4}$ Multiple sections were taken for microscopic examination from the left main coronary artery and from the proximal, middle, and distal regions of the left anterior descending, left circumflex, and right coronary arteries. In addition, in each specimen, myocardial samples were obtained from the anteroseptal, anterolateral, and inferior walls of the left ventricle, including both mitral papillary muscles. Sections from the ascending aorta, aortic arch vessels, descending thoracic aorta, main pulmonary artery, and right and left pulmonary arteries were also processed for evaluation of arterial dysplasia or other abnormalities.

Tissues were processed routinely for examination with a light microscope, and sections were stained with hematoxylin and eosin. In addition, all arteries were stained with elastic-van Gieson, and myocardium was stained with trichrome. Coronary artery obstruction was graded on the basis of the percent of luminal narrowing in cross-sectional area, in $25 \%$ increments for grades 1 through 4 . Aortic medial dysplasia and myocardial fibrosis were graded semiquantitatively as absent (grade 0) or as mild, moderate, or severe (grades 1 through 3). Moreover, for each specimen, we reviewed the patient's clinical chart and autopsy report and recorded the age, gender, and clinical diagnoses.

\section{Results}

Clinical features. All five patients were male. The mean age at the time of death was 10 years (range $1 \frac{1}{2}$ to 39 years, median 3 years). The four children had Williams-Beuren syndrome, two familial and two sporadic (see Table I). Additional patient data including the year of autopsy, the type of supravalvular aortic stenosis, and associated cardiovascular and noncardiovascular lesions are summarized in Table I.

Three patients had the discrete form of supravalvular 

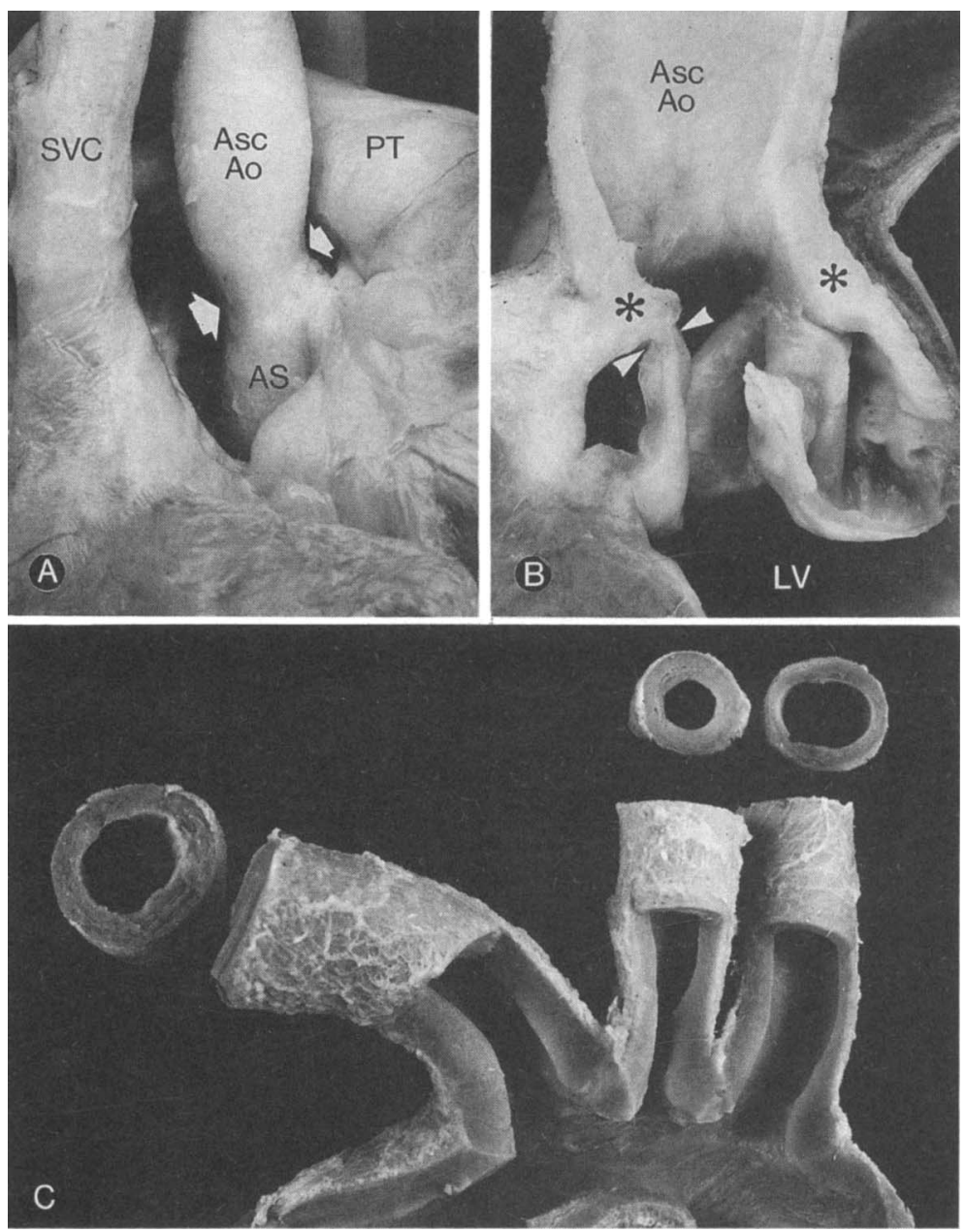

Fig. 2. Gross pathology of supravalvular aortic stenosis. A and B, Discrete form shows external constriction (A, arrows $)$ and internal thickening at level of aortic sinotubular junction $(\mathbf{B}, *)$. Note focal fusion of aortic cusp to junctional ridge (arrow). C. Diffuse form exhibits marked thickening of aortic wall and walls of brachiocephalic branches. $A s c A o$, Ascending aorta; $A S$, aortic sinus; $L V$, left ventricle; $P T$, pulmonary trunk; $S V C$, superior vena cava.

Table II. Microscopic grades of coronary artery stenosis and myocardial fibrosis in five male patients with supravalvular aortic stenosis

\begin{tabular}{|c|c|c|c|c|c|c|c|c|}
\hline \multirow[b]{2}{*}{ Case No. } & \multirow[b]{2}{*}{ Age $(y r)$} & \multirow[b]{2}{*}{ SVAS type } & \multicolumn{4}{|c|}{ Grade of stenosis } & \multicolumn{2}{|c|}{ Grade of LV fibrosis } \\
\hline & & & $L M A$ & $L A D$ & $L C x$ & $R C A$ & Pap muscle & Subendo \\
\hline 1 & 2 & Diffuse & 3 & 3 & 3 & 3 & 2 & 2 \\
\hline 2 & 3 & Diffuse & 3 & 1 & 2 & 2 & 2 & 1 \\
\hline 3 & $1 \frac{1 / 2}{2}$ & Discrete & 1 & 1 & 1 & 3 & 1 & 1 \\
\hline 4 & 5 & Discrete & 1 & 1 & 1 & 1 & 0 & 0 \\
\hline 5 & 39 & Discrete & 3 & 4 & 3 & 4 & 3 & 3 \\
\hline
\end{tabular}

$L A D$, Left anterior descending coronary artery; $L C X$, left circumflex coronary artery; $L M A$, left main coronary artery; $P a p$ muscle, mitral papillary muscles; $R C A$, right coronary artery; $S$ ubendo, subendocardial myocardium; $S V A S$, supravalvular aortic stenosis.

aortic stenosis (Fig. 2). Two of these had a history of sudden death, one during repair of hypospadia (case 4) and the other spontaneously (case 3 ). Patient 5 died of an acute myocardial infarction on the first day after aortic valve replacement and mitral valvuloplasty, and 9 years after enlargement of the ascending aorta with a teardropshaped pericardial patch and decalcification of a focally calcified bicuspid aortic valve. 

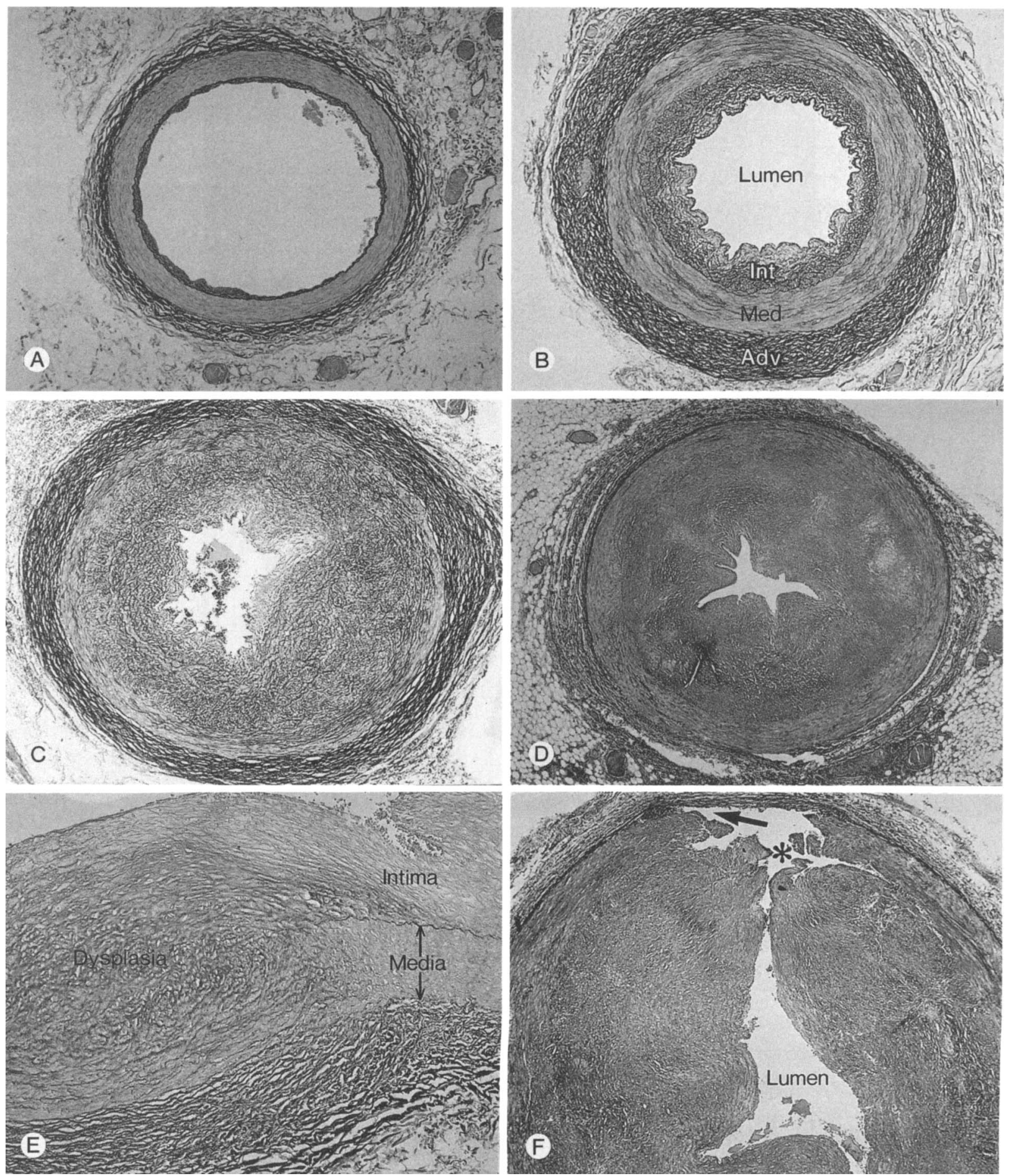

Fig. 3. Photomicrographs of coronary arteries in supravalvular aortic stenosis. A. Normal coronary artery, for comparison. B. Distinct intima (Int), media $(M e d)$, and adventitia $(A d v)$, with thickening of all three layers. C. Severe luminal obstruction caused by wall thickening, with loss of internal elastic membrane, loss of distinction between intima and media, and disorganized (dysplastic) intimal-medial proliferation. D. Severe stenosis caused by dysplasia and atherosclerosis in 39-year-old man. E. Transition from three distinct arterial layers (right) into thickened and disorganized wall with loss of distinction between intima and media (left). F. Arterial dysplasia associated with focal acute intimal tear $(*)$ and minor intramedial dissection (arrow). (Elastic-van Gieson; A, $\times 35 ; \mathbf{B}$ and $\mathbf{C}, \times 30 ; \mathbf{D}, \times 15$; $\mathbf{E}, \times 60 ; \mathbf{F}, \times 20$.) 


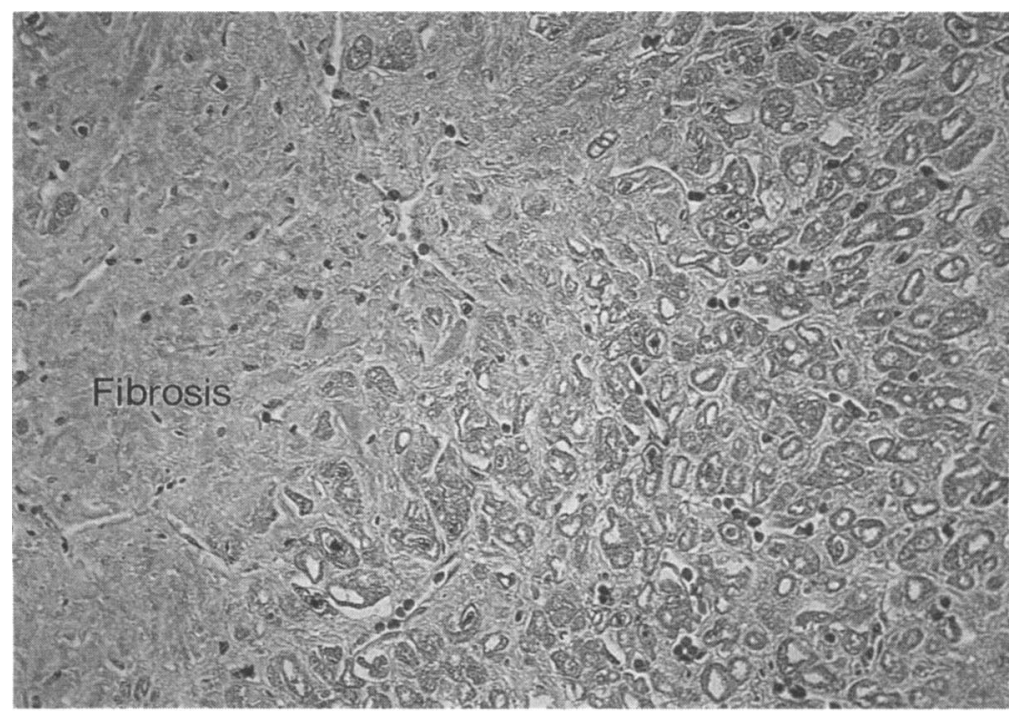

Fig. 4. Photomicrograph of myocardium in supravalvular aortic stenosis with coronary artery obstruction. Chronic ischemic changes include replacement fibrosis (left) and sarcoplasmic vacuolization of myocytes (right) from mitral papillary muscle. (Hematoxylin and eosin; $\times 200$.)

The remaining two patients (cases 1 and 2) both had Williams-Beuren syndrome and the diffuse form of supravalvular aortic stenosis; both died intraoperatively of heart failure, one during insertion of a left ventricularsupraceliac aortic valved conduit and the other during enlargement of the ascending aorta with a teardropshaped Teflon patch. In both specimens, the ascending aorta, aortic arch, and proximal aortic arch vessels were diffusely thickened and their lumina were markedly narrowed (see Fig. 2).

Pathologic features. Coronary arterial lesions were categorized as congenital or acquired. Congenital lesions consisted of intimal hyperplasia $(n=5)$, intimal fibrosis $(n=4)$, indistinct intimal-medial junction with loss of internal elastic lamina $(n=5)$, medial hypertrophy $(n=5)$, medial disorganization with "woven" fibroelastic pattern $(n=5)$, and adventitial fibroelastosis $(n=5)$ (Fig. 3). In severe cases, this constellation of lesions resulted in a thickened arterial wall that appeared similar in structure to the ductus arteriosus.

In the coronary arteries of the four youngest patients (aged 11/2 to 5 years, mean 3 years), there were varying degrees of intimal hyperplasia, intimal fibrosis, and medial hypertrophy. Generally, the grade of luminal narrowing (Table II) was greater in the proximal segments than in the distal segments. In the 1/2-year-old patient with left ostial narrowing caused by focal adherence of the left aortic cusp to the supravalvular ridge, a lesser degree of intimal hyperplasia and intimal fibrosis was present in the left than in the right coronary system. The heart of the 39-year-old patient showed severe intimal hyperplasia and focal calcific atherosclerosis of the coronary arteries; in addition, there was a dissection of the distal right coronary artery (see Fig. 3).

All cases exhibited left ventricular hypertrophy. Ischemic myocardial lesions consisted of fibrosis of the anterolateral $(n=4)$ and posteromedial $(n=4)$ papillary muscles, with or without focal calcification, and microfocal fibrosis of the left ventricular subendocardium ( $n=4)$ (Fig. 4). In the heart of the 39-yearold patient, an acute myocardial infarction without coronary thrombosis was superimposed on moderate to severe focal subendocardial fibrosis. In one heart (case 4), no ischemic myocardial injury was present, but mild lymphocytic myocarditis with focal myocyte necrosis was evident.

The ascending aorta, aortic arch, main pulmonary artery, and left and right pulmonary arteries showed mild to moderate medial dysplasia $(n=5)$ and medial fibrosis $(n=3)$. Dysplastic vessels were characterized by medial thickening, with haphazard (nonparallel) arrangement of smooth muscle cells, increased collagen deposition, and markedly decreased elastin content (Fig. 5). In the two specimens with the diffuse form of supravalvular aortic stenosis, the proximal aortic arch vessels were also dysplastic. Except for medial thickening in the two cases of diffuse supravalvular aortic stenosis, no differences in the histologic findings were detected between cases with or without Williams-Beuren syndrome. The descending thoracic aorta was normal (cases 1 to 4) (Fig. 5) or showed mild focal dysplasia (case 5). In one heart (case 1), a localized dissection of the ascending aorta was associated with acute luminal narrowing without external rupture. 


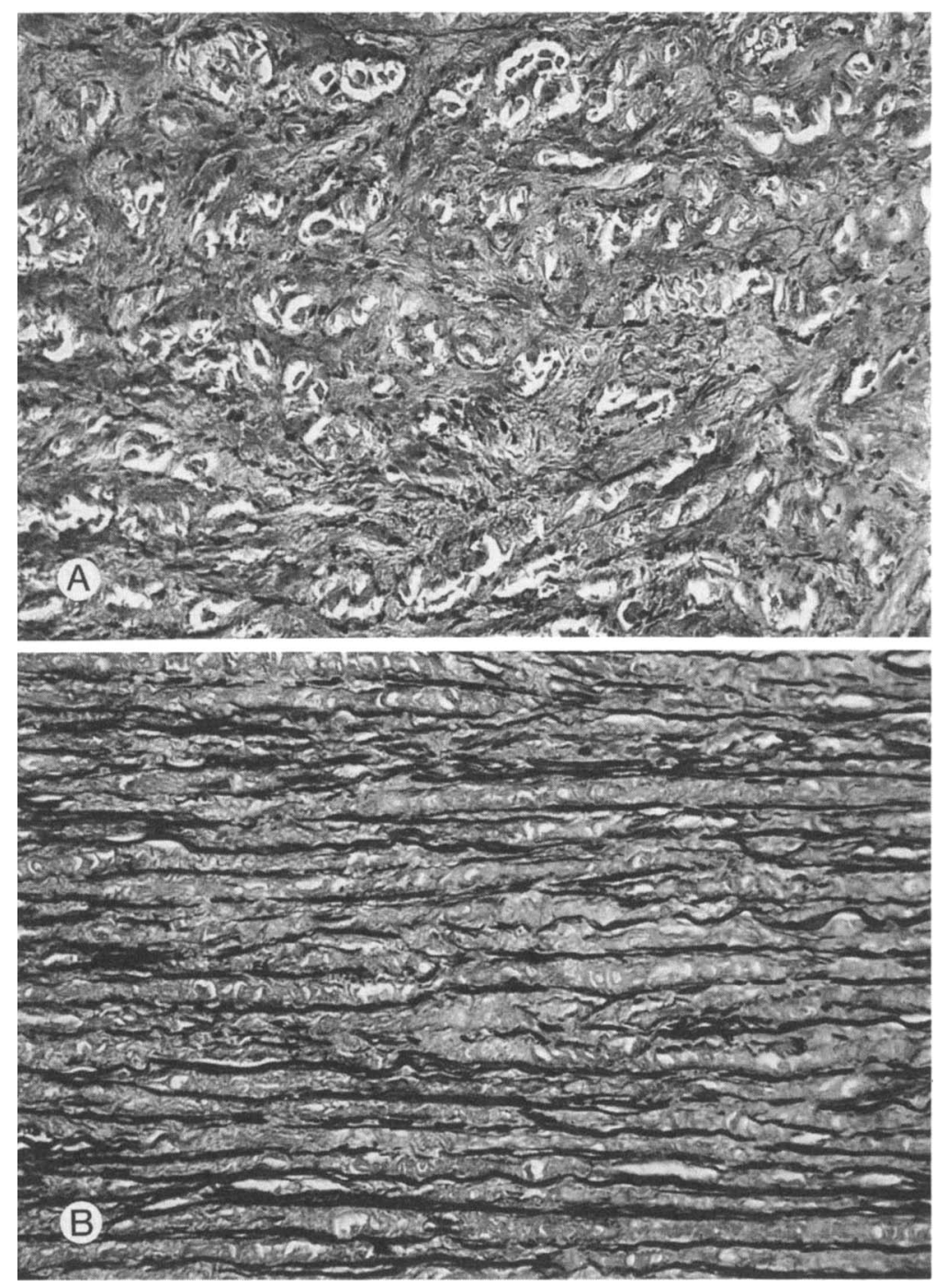

Fig. 5. Photomicrograph of ascending aorta in supravalvular aortic stenosis. A, Marked disorganization and loss of elastic elements. B, Normal tissue, from distal portion of descending thoracic aorta in same patient, for comparison (Elastic-van Gieson; $\times 260$.)

\section{Discussion}

In patients with supravalvular aortic stenosis, blood flow to the aortic sinuses and coronary ostia may be obstructed because of adhesion of the valve cusps to the stenotic supravalvular ridge. ${ }^{5-11}$ Left ostial stenosis caused by this mechanism was observed in one of the specimens in the present series. In the absence of such ostial obstruction, the coronary arteries are exposed to both an elevated systolic pressure and a high pulse pressure, which represent appreciable distending forces that may lead to dilatation and tortuosity. In our recently reported series of 80 patients with supravalvular aortic stenosis, dilatation of the right coronary artery was found in $29 \%$ of the patients and dilatation of the left coronary artery in $20 \%{ }^{6}$ As in other series, the higher incidence of dilatation of the right versus the left coronary artery was due to the higher prevalence of left ostial stenosis., ${ }^{6}, 11$

Other secondary structural changes in the coronary arteries that are caused by high systolic pressure in the aortic root include intimal hyperplasia and atherosclerosis. The high smooth muscle content of the media of the coronary artery (as opposed, for instance, to the media of the internal mammary artery, which is mainly elastic) may predispose to these early occurring and progressive processes. ${ }^{12,13}$ The spectrum of coronary artery disease in supravalvular aortic stenosis, as observed 
in the current series, may be explained by the difference in exposure time among the cases. An additional potential complication of the high pressure to which the coronary arteries are exposed is focal dissection of the arterial wall, as occurred in the 39-year-old patient in the present series.

Data from this study illustrate the prevalence of ischemic heart disease among patients with supravalvular aortic stenosis. With coexistent left ventricular hypertrophy, lesions of myocardial ischemia often begin to develop in early childhood.

In patients with supravalvular aortic stenosis as part of the Williams-Beuren syndrome, the most common associated anomalies consist of stenoses in the proximal aortic arch vessels and pulmonary arteries. ${ }^{1-3,5}$ In the present study, stenoses of the innominate, left common carotid, and left subclavian arteries were observed in two patients with the Williams-Beuren syndrome and the diffuse form of supravalvular aortic stenosis. Proximal and distal pulmonary artery stenoses, extending beyond the first lobar branches, were found in the specimens of all four patients with the Williams-Beuren syndrome. Severe flow disturbance distal to the obstructing ridge at the sinotubular junction may cause dissection of the dysplastic aortic wall, as was seen in a 2-year-old boy in the present series.

In addition, supravalvular aortic stenosis has been reported to be associated with abnormalities of the mitral valve. Becker and colleagues ${ }^{14}$ reported on three patients who had uniform thickening of the mitral valve and protrusion of the mitral valve toward the left atrium. The thickening was caused by an increase in fibrous tissue, and two of their three patients also had fibrous chordal thickening. Similar findings have been reported by others. ${ }^{5,15}$ In our series, two patients with Williams-Beuren syndrome had mitral valve abnormalities consisting of thickening of both leaflets and the attached chordae tendineae.

On the basis of the pathologic findings in the coronary arteries, myocardium, and ascending aorta as presented in this study, we recommend operative treatment of supravalvular aortic stenosis in early childhood, to prevent accelerated coronary artery disease, its detrimental ischemic effects on the myocardium, and dissection of the ascending aorta or coronary arteries. Our experience ${ }^{6,10}$ and that of others ${ }^{16-18}$ indicate that enlargement of the aortic root with a teardrop-shaped or pantaloon-shaped patch leads to excellent long-term results. Alternatively, patching of the three aortic sinuses ${ }^{19}$ or circular excision of the stenosis at the level of the sinotubular junction followed by end-to-end anastomosis of the ascending aorta to the aortic root ${ }^{20}$ may restore a more anatomic configuration to the aortic root, but long-term results are not available. In diffuse supravalvular aortic stenosis, the entire ascending aorta should be enlarged with a patch, often with extension into the aortic arch and one or more of the proximal aortic arch vessels. ${ }^{6}$ Alternatively, a conduit may be inserted from the ascending to descending aorta with side branches to stenotic arch vessels. $^{6}$

\section{REFER E N C ES}

1. Williams JCP, Barratt-Boyes BG, Lowe JB. Supravalvular aortic stenosis. Circulation 1961;24:1311-8.

2. Beuren AJ, Apitz J, Harmjanz D. Supravalvular aortic stenosis in association with mental retardation and a certain facial appearance. Circulation 1962;26:1235-40.

3. Beuren AJ, Schulze C, Eberle P, Harmjanz D. Apitz J. The syndrome of supravalvular aortic stenosis, peripheral pulmonary stenosis, mental retardation and similar facial appearance. Am J Cardiol 1964;13:471-83.

4. Neufeld HN, Wagenvoort CA, Ongley PA, Edwards JE. Hypoplasia of ascending aorta: an unusual form of supravalvular aortic stenosis with special reference to localized coronary arterial hypertension. Am J Cardiol 1962;10:74651.

5. Blieden LC, Lucas RV Jr, Carter JB, Miller K, Edwards JE. A developmental complex including supravalvular stenosis of the aorta and pulmonary trunk. Circulation 1974;49:585-90.

6. Van Son JAM, Danielson GK, Puga FJ, et al. Supravalvular aortic stenosis: long-term results of surgical treatment. J Thorac Cardiovasc Surg 1994;107:103-15.

7. Denie JJ, Verheugt AP. Supravalvular aortic stenosis. Circulation 1958;18:902-8.

8. Morrow AG, Waldhausen JA, Peters RL, Bloodwell RD, Braunwald E. Supravalvular aortic stenosis: clinical, hemodynamic and pathologic observations. Circulation 1959; 20:1003-10.

9. Peterson TA, Todd DB, Edwards JE. Supravalvular aortic stenosis. J THORAC Cardiovasc SuRG 1965;50:73441.

10. Rastelli GC, McGoon DC, Ongley PA, Mankin HT, Kirklin JW. Surgical treatment of supravalvular aortic stenosis: report of 16 cases and review of the literature. J THORAC CARDiovasc SuRg 1966;51:873-82.

11. Zalzstein E, Moes CAF, Musewe NN, Freedom RM. Spectrum of cardiovascular anomalies in Williams-Beuren syndrome. Pediatr Cardiol 1991;12:219-23.

12. Van Son JAM, Smedts F, Vincent JG, van Lier HJJ, Kubat K. Comparative anatomic studies of various arterial conduits for myocardial revascularization. J THORAC CARDIOVASC SURG 1990;99:703-7.

13. Van Son JAM, Smedts F, de Wilde PCM, et al. Histological study of the internal mammary artery with emphasis on its suitability as a coronary artery bypass graft. Ann Thorac Surg 1993;55:106-13.

14. Becker AE, Becker MJ, Edwards JE. Mitral valvular abnormalities associated with supravalvular aortic steno- 
sis: observations in 3 cases. Am J Cardiol 1972;29: 90-4.

15. Sissman NJ, Neill CA, Spencer FC, Taussig HB. Congenital aortic stenosis. Circulation 1959;19:458-68.

16. Doty DB, Polansky DB, Jenson CB. Supravalvular aortic stenosis: repair by extended aortoplasty. J THORAC CARDIOVASC SURG 1977;74:362-71.

17. Sharma BK, Fujiwara H, Hallman GL, Ott DA, Reul GJ, Cooley DA. Supravalvar aortic stenosis: a 29-year review of surgical experience. Ann Thorac Surg 1991;51: 1031-9.
18. Myers JL, Waldhausen JA, Cyran SE, Gleason MM, Weber HS, Baylen BG. Results of surgical repair of congenital supravalvular aortic stenosis. J THORAC CARDIOVASC SURG 1993;105:281-8.

19. Kirklin JW, Barratt-Boyes BG. Congenital aortic stenosis. In: Kirklin JW, Barratt-Boyes BG, eds. Cardiac surgery. 2nd ed. New York: Churchill Livingstone, 1993:1195237.

20. Chard RB, Cartmill TB. Localized supravalvular aortic stenosis: a new technique for repair. Ann Thorac Surg 1993;55:782-4.

\section{Bound volumes available to subscribers}

Bound volumes of THE JOURNAL OF THORACIC AND CARDIOvASCULAR SURGERY are available to subscribers (only) for the 1994 issues from the Publisher, at a cost of $\$ 82.50$ for domestic, $\$ 106.28$ for Canadian, and $\$ 100.50$ for international subscribers for Vol. 107 (January-June) and Vol. 108 (July-December). Shipping charges are included. Each bound volume contains a subject and author index and all advertising is removed. Copies are shipped within 60 days after publication of the last issue of the volume. The binding is durable buckram with the JOURNAL name, volume number, and year stamped in gold on the spine. Payment must accompany all orders. Contact Mosby-Year Book, Inc., Subscription Services, 11830 Westline Industrial Drive, St. Louis, Missouri 63146-33I8, USA; phone 1 (800) 4534351 or (314) 453-4351.

Subscriptions must be in force to qualify. Bound volumes are not available in place of a regular JourNal subscription. 